American Journal of Applied Sciences 6 (12): 2071-2077, 2009

ISSN 1546-9239

(C) 2009 Science Publications

\title{
Dose Response and Optical Properties of Dyed Poly Vinyl Alcohol-Trichloroacetic Acid Polymeric Blends Irradiated with Gamma-Rays
}

\author{
Susilawati and Aris Doyan \\ Department of Physic, Mataram University, Lombok, Nusa Tenggara Barat, Indonesia
}

\begin{abstract}
Problem statement: The effects of gamma irradiation on optical properties of cresol-red dyed Poly Vinyl Alcohol (PVA) blended with Trichloroacetic Acid (TCA) for possible use in dosimetry and measurement of radiation dose in gamma rays have been studied using both Raman spectroscopy and UV-Visible spectrophotometer method. Approach: The dosimeters are composed of Poly Vinyl Alcohol (PVA), Trichloroacetic Acid (TCA) at various concentrations are 20, 25, 30 and $35 \%$, and acid-base indicator cresol-red dyed. Results: The dosimeters were irradiated to doses up $12 \mathrm{kGy}$ using ${ }^{60} \mathrm{Co}$ gamma ray source at a constant dose rate. The polymeric films undergo color change from purple to yellow due to radiation-induced acid formation. The molecular vibrational spectra were measured using Raman spectroscopy, resulting in a decrease of the Raman intensity inelastic scattering of $\mathrm{C}-\mathrm{Cl}$ molecular stretching from TCA with increasing dose. The absorption spectra were measured using UV-visible spectrophotometer in the wavelength range $350-700 \mathrm{~nm}$, resulting in a decrease of the absorbance at $575 \mathrm{~nm}$ band peak with increasing dose. The dose sensitivity $\mathrm{D}_{0}$ increases with increasing TCA concentration for both scattering and absorption methods. The optical absorption studies show that the direct and indirect optical energy band gaps and optical activation energies are dependent on dose and TCA concentration. Conclusion: The shift in the optical band gap $\mathrm{E}_{\mathrm{g}}$ values towards lower energy with radiation dose leads to a shift of the optical activation energy DeltaE value towards the lower energy region with increasing dose. The optical band gap $\left(\mathrm{E}_{\mathrm{g}}\right)$ and the absorption edge decrease with increasing dose attributed to the structural disorder of polymer blends due to dehydrochlorination of trichloroacetic acid with increasing dose. The energy width of the tail of localized state in the forbidden band gap was evaluated using the Urbach-edges method. It was found that the activation energy (DeltaE) is less dependent of radiation dose but strongly dependent on concentration of blends.
\end{abstract}

Key words: Dose-response, optical properties, polymer blends, absorption spectra, optical band gap, activation energy

\section{INTRODUCTION}

Solid polymer blends have been considerably studied in view of their wide potential application for novel systems and devices ${ }^{[1-3]}$. Suitable addition of dopants, blends, or copolymers to the polymer matrix, the electrical, electrochemical and optical properties of these materials could be selectively modified for particular properties in various applications ${ }^{[4-8]}$. It is well known that molecular structure and the physical properties of polymer blends could be modified by ionising radiations ${ }^{[9,10]}$. Ionization of atoms and scission of molecules occur leading to the formation of charged species both ionic and free radicals. Raman scattering studies can provide information on the type of molecular species of the blends, while optical absorption studies are important to provide details of the electronic band structures, localized states and type of optical transitions, making these materials very attractive for chemical sensors in the detection of ionic species and for display panels ${ }^{[11-13]}$.

Several dyed Poly Vinyl Alcohol (PVA) blends containing chlorine have been investigated for possible use in dosimetry for measurement of radiation dose in $\gamma$-ray and electron beam facilities ${ }^{[14-16]}$. They contain $\mathrm{pH}$-indicating dye and water-soluble chlorinecontaining substances. The blends are dehydrochlorinated and formed acid, thereby decreasing the $\mathrm{pH}$ and causing the acid-sensitive dye to change color. In this article, we report the molecular vibrational and optical characteristics of cresol-red dyed PVA-TCA blends, which undergo color change from

Corresponding Author: Susilawati, Department of Physics, University Mataram, Lombok, Nusa Tenggara Barat, Indonesia 2071 
purple (the alkaline form of the dye) to yellow (the acidic form of the dye) upon irradiation with $\gamma$-rays.

\section{MATERIALS AND METHODS}

The stock solution of cresol red dye was prepared by dissolving $0.08 \mathrm{~g}$ of cresol-red indicator (product of fisher Chemical UK) in $15 \mathrm{~mL}$ of aqueous $\mathrm{NaOH}$ solution $\left([\mathrm{NaOH}]=0.1 \mathrm{~mol} \mathrm{~L}^{-1}\right)$ and the volume was completed by ethanol in a $50 \mathrm{~mL}$ volumetric flask. PVA from SIGMA $\mathrm{Mw}=70,000 \mathrm{~g} \mathrm{~mol}^{-1}, 99-100 \%$ hydrolyzed, was used as received. PVA powder was dissolved in double distilled water at $90^{\circ} \mathrm{C}$. The solution was stirred throughout at that temperature for $2 \mathrm{~h}$ and then left to cool. A $1 \mathrm{~mL}$ of the indicator stock solution was added and kept well stirred at room temperature for about $2 \mathrm{~h}$. To each $50 \mathrm{~mL}$ of the well-mixed solution, $20-35 \%$ of TCA were added, stirred and poured onto a horizontal glass plate and dried at room temperature for about $72 \mathrm{~h}$. After drying, the films were peeled off and cut into several pieces, stored and ready for irradiation. The average thickness of the films was found to be about $70 \mu \mathrm{m}$.

The film irradiations were carried out in the ${ }^{60} \mathrm{Co} \gamma$ rays chamber. The absorbed dose rate was calibrated using Fricke dosimetry method to be $9.39 \mathrm{kGy} \mathrm{h}^{-1}$. For each dose the film samples of different TCA concentrations were placed simultaneously at the centre of the chamber surrounded with polyethylene block for radiation equilibrium purposes. The samples were exposed at different doses up to $12 \mathrm{kGy}$ at room temperature.

The molecular vibrational spectra were measured using Raman spectrometer (RSI 2001 B, Raman system, Inc.,) equipped with $532 \mathrm{~nm}$ solid-state diode green lasers. This spectrometer was chosen for its high sensitivity since the Raman signal intensity is inversely proportional to $\lambda^{4}$, where $\lambda$ is the wavelength of the visible laser. Low power laser is preferred to avoid excessive sample heating. Laser excitation and signal collection was performed using a probe head at a working distance between 8 and $10 \mathrm{~cm}$ in a dark room. Grams/32, version 6 software was used to analyze the spectra. All spectra were corrected for base line; smoothing and Fourier Transform (FT).

The absorption spectra of the unirradiated and irradiated film dosimeters were measured using UVVisible spectrometer (Shimadzu, Model 1601) in the wavelength range $350-700 \mathrm{~nm}$.

\section{RESULTS AND DISCUSSION}

Visible absorption dose response:

Raman scattering dose response: The effects of radiation on dyed PVA-TCA blends were measured using Raman spectroscopy for the scattering intensity of molecular vibrational of $\mathrm{C}-\mathrm{Cl}$ bond stretching of TCA. Upon irradiation, TCA will undergo dehydrochlorinated, which increases chlorine ions in the film. Halogen derivatives of hydrocarbons, as in our case $\mathrm{C}-\mathrm{Cl}$ bond, are more radiosensitive compared with $\mathrm{C}=\mathrm{O}, \mathrm{C}-\mathrm{C}$ or $\mathrm{C}-\mathrm{OH}$ bond of TCA. Three fingerprints of C-Cl stretching band peaks at 619,796 and $1002 \mathrm{~cm}^{-1}$ were observed corresponding to the vibrational energies of $0.077,0.099$ and $0.125 \mathrm{eV}$ respectively as shown in Fig. 1.

The $\mathrm{C}-\mathrm{Cl}$ stretching intensity decreases with dose as shown in Fig. 2. The dose-response curves of $\mathrm{C}-\mathrm{Cl}$ stretching may be fitted to equation:

$$
\mathrm{y}=\mathrm{y}_{0} \mathrm{e}^{-\mathrm{D} / \mathrm{D}_{0}}
$$

Where:

$\mathrm{y}=$ The Raman intensity at a given dose $\mathrm{D}$

$\mathrm{y}_{0}=$ The intensity at zero dose

$\mathrm{D}_{0}=\mathrm{A}$ constant known as the dose sensitivity parameter

From the fitting of the dose-response curves we obtained a linear relationship between $\mathrm{D}_{0}$ values and TCA concentrations is shown in Fig. 3. The gradient of the graph is $0.065 \mathrm{kGy}$ per concentration of TCA.

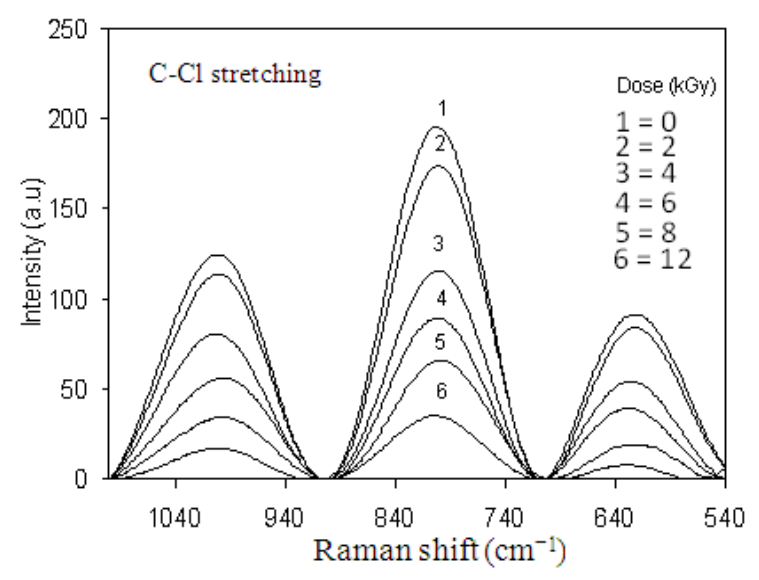

Fig. 1: Raman spectra of $\mathrm{C}-\mathrm{Cl}$ molecular vibrations at 619, 796 and $1002 \mathrm{~cm}^{-1}$ bands 
Am. J. Applied Sci., 6 (12): 2071-2077, 2009

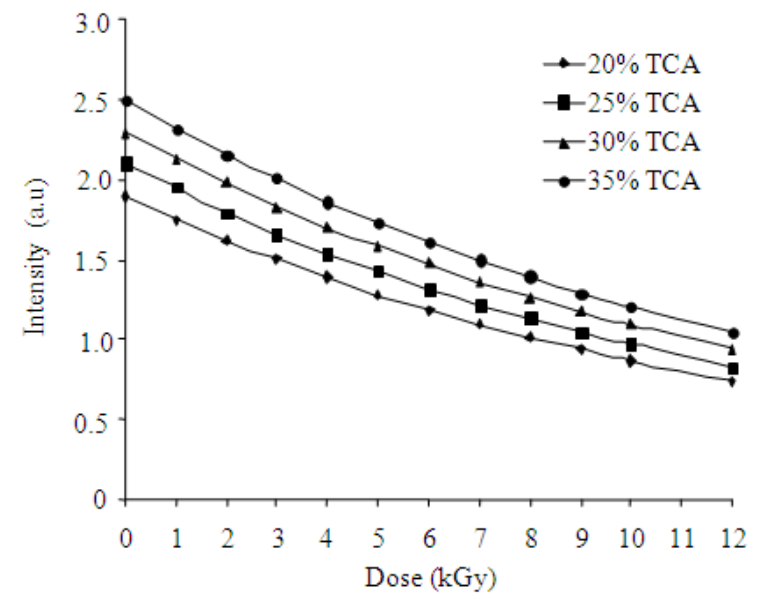

Fig. 2: $\mathrm{C}-\mathrm{Cl}$ stretching dose-response curves of dyed PVA-TCA blends at different TCA concentrations

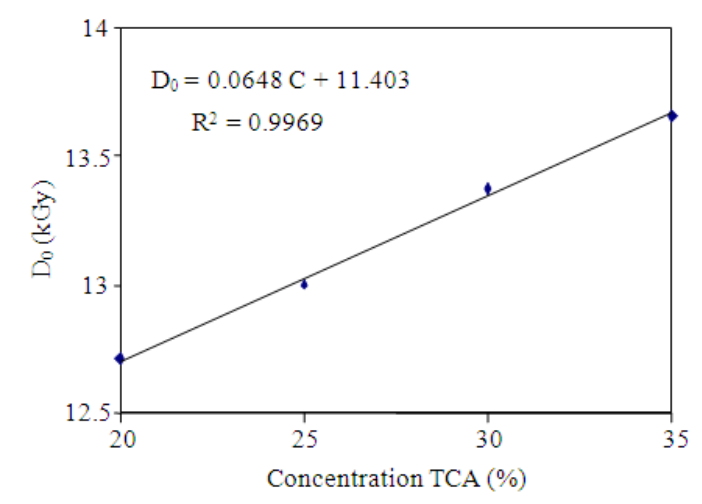

Fig. 3: The values of sensitive dose $D_{0}$ derived from $C$ $\mathrm{Cl}$ stretching dose-response curves of dyed PVA-TCA film blends at different TCA concentrations

Visible absorption dose response: The effects of radiation on optical properties of dyed PVA-TCA blends were measured using UV-visible spectrometer. The absorption spectra are shown in Fig. 4. The blends changed color from purple to yellow as the dose increases. No change in color was observed for the dyed PVA films that are not blended with TCA. Due to complex molecular structures of the polymer blends, the superposition of electronic and vibrational transitions produce typical overlapping continuous UVvisible absorption bands. The absorption spectra produced two absorption bands in the visible region. These visible bands correspond to the excitation of outer electrons, which provide information on the electronic transitions of the molecules in the samples.

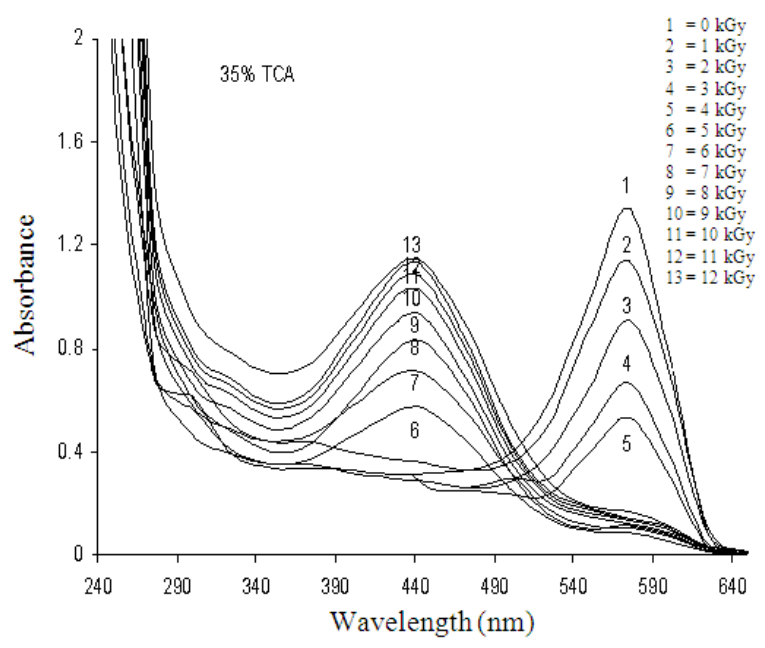

Fig. 4: Spectra of absorbance of dyed PVA-TCA blends measured at wavelength range 240$640 \mathrm{~nm}$ for different doses

They are attributed to the $\pi-\pi^{*}$ transitions and to the presence of ions in the polymer ${ }^{[17,18]}$. Dehydrochlorinated of TCA and hydrolysis of water molecules are responsible for the formation of acid, which reacts with the dye and causes the change in the dye structure leading to color change of the blended films. The dominant absorbance at $280 \mathrm{~nm}$ band of UV region increases with dose. UV absorption is mainly due to electron (or anion) transitions from the top of the valence band to the bottom of the conduction band ${ }^{[19]}$. The absorbance increases exponently with dose for $438 \mathrm{~nm}$ band and decreases exponently with dose for $575 \mathrm{~nm}$ band. As the dose increases, more chlorine ions break from carbon of TCA and radiation-induced $\mathrm{H}$ and $\mathrm{OH}$ free radicals are generated from the hydrolysis of water molecules. They then combined to form acid, which lowers the $\mathrm{pH}$ of the blends. Figure 5 shows the absorbance-dose response at $575 \mathrm{~nm}$ band for different concentrations of TCA.

The dose-response curves of absorption band at $575 \mathrm{~nm}$ decrease exponentially with dose and the fitting of equation $\mathrm{y}=\mathrm{y}_{0} \mathrm{e}^{-\mathrm{D} / \mathrm{D} 0}$ results in the dose sensitivity parameter $\mathrm{D}_{0}$, which increases with concentration of TCA as shown in Fig. 6. The gradient is slightly higher than the gradient obtained from Raman spectroscopy method. Lower $\mathrm{D}_{0}$ values of absorption measurement at a given TCA concentration indicate that the absorption method is more sensitive than the Raman scattering method at a given dose. 
Am. J. Applied Sci., 6 (12): 2071-2077, 2009

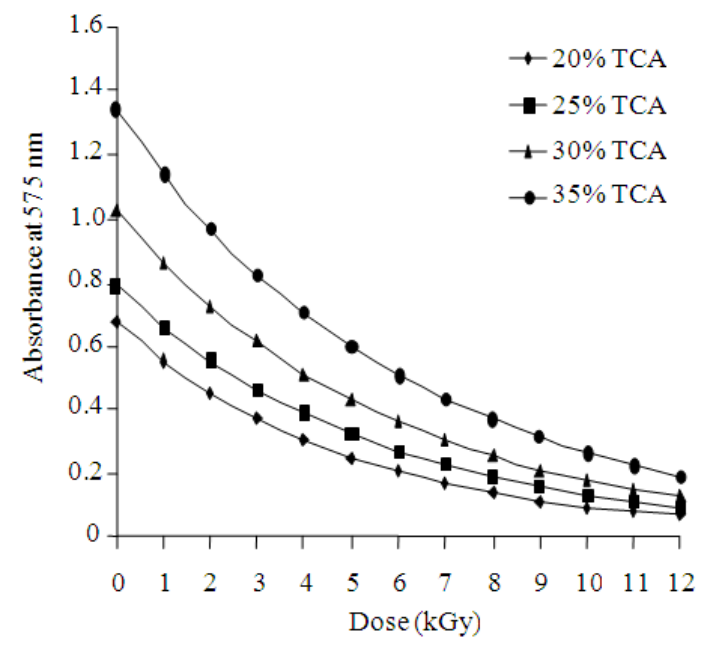

Fig. 5: Absorption at $575 \mathrm{~nm}$ band dose-response curves of dyed PVA-TCA film blends at different TCA concentrations

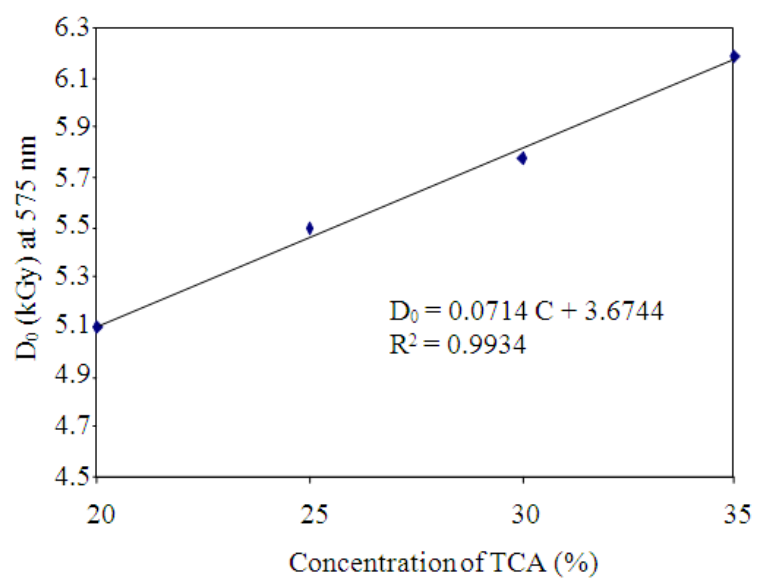

Fig. 6: The sensitive dose $D_{0}$ derived from $575 \mathrm{~nm}$ absorption band dose-response curves of dyed PVA-TCA blends at different TCA concentrations

Optical properties: The absorption of the $529 \mathrm{~nm}$ band increases with increasing dose. These visible bands correspond to the excitation of outer electrons, which provide information on the electronic transitions of the molecules in the blend samples. They are attributed to the $\pi-\pi^{*}$ transitions and to the presence of ions in the polymer ${ }^{[18]}$. Following irradiation with the dose exceeding the critical dose depending on the blend concentration, the irradiated films undergo color change from yellow to red, indicating strong acid formation.

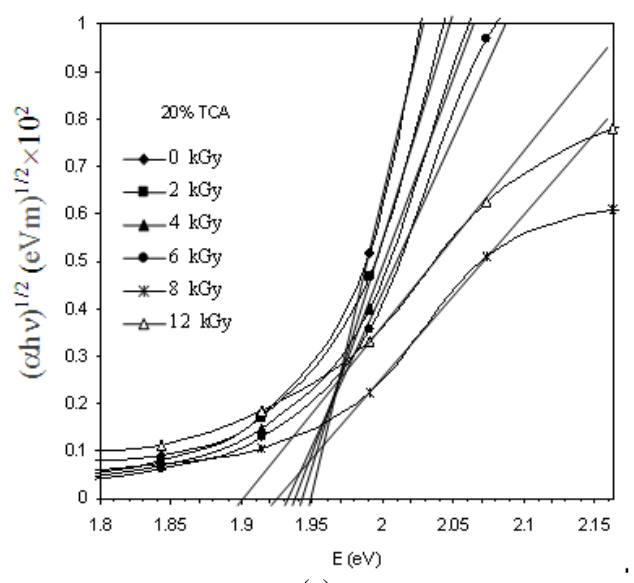

(a)

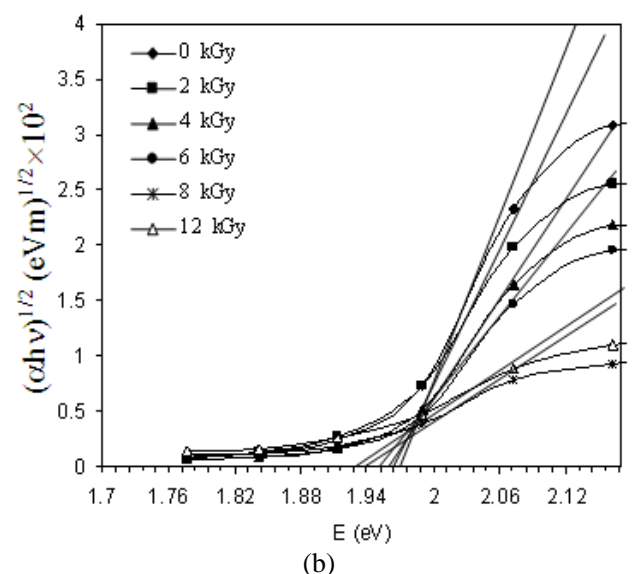

Fig. 7: Direct allowed transition $(\alpha h v)^{1 / 2}$ versus hv for (a) 20\% TCA and (b) 35\% TCA at different doses

The absorption coefficient $\alpha(v)$ of dyed PVA-TCA blends were taken from the optical absorption spectrum using relation:

$\alpha(v)=2.303 \mathrm{~A} / \mathrm{d}$

Where:

$\mathrm{d}=$ The sample thickness in $\mathrm{cm}$

A = Defined by:

$$
\mathrm{A}=\log \left(\mathrm{I}_{0} / \mathrm{I}\right)
$$

where, $I_{0}$ and $I$ are the intensity of the incident and transmitted beams respectively. Analysis of optical absorption spectra could reveal the energy gap $E_{g}$ between the Conduction Band (CB) and the Valence Band (VB) due to direct and indirect transitions of both crystalline and amorphous materials. The absorption 
edge coefficient $\alpha(v)$ is a function of photon energy and obeys Mott and Davis's model (Mott and Davis, 1970):

$$
\alpha(v) h v=B\left(h v-E_{g}\right)^{m}
$$

Where:

$h v=$ The energy of the incidence photon

$\mathrm{h}=$ The Planck constant

$\mathrm{E}_{\mathrm{g}}=$ The optical energy band gap

$\mathrm{B}=\mathrm{A}$ constant known as the disorder parameter which is nearly independent of the photon energy

Parameter $\mathrm{m}$ is the power coefficient with the value that is determined by the type of possible electronic transitions, i.e., $\mathrm{m}=1 / 2,3 / 2$, 2 or $1 / 3$ for direct allowed, direct forbidden, indirect allowed and indirect forbidden respectively ${ }^{[19,21]}$.

The direct optical band gap can be evaluated from the linear plots of $(\sigma \mathrm{hv})^{1 / 2}$ versus hv as illustrated in Fig. $7 \mathrm{a}$ and $\mathrm{b}$ for $20 \%$ TCA and $40 \%$ TCA respectively at different doses. The extrapolations of the lines of $(\sigma h v)^{1 / 2}$ versus hv for which $(\alpha h v)^{1 / 2}=0$, give the direct optical band gap, which is a function of dose as illustrated in Fig. 8 for all concentrations. The direct band gap increases with TCA concentration and decreases with increasing dose. The indirect optical band gaps were evaluated from $(\sigma h v)^{1 / 2}$ versus hv as illustrated in Fig. 9a and b for 20\% TCA and 35\% TCA respectively at different doses. The relationship between the indirect value of optical band gaps and dose at different TCA concentrations is illustrated in Fig. 10. The relationship has similar features as those of the direct energy band gap that the indirect band gap increases with TCA concentration and decreases with increasing dose. However the indirect band gap is greater than the direct band gap. Therefore,

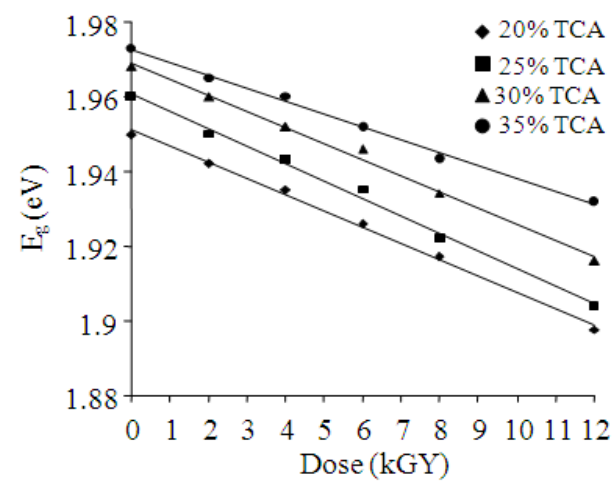

Fig. 8: Variation of the direct energy band gaps with dose at different percentages of TCA the optical band gaps are dose and blend concentration dependent for both direct and indirect allowed transitions. A decrease in the energy band gap with increasing dose may be attributed to an increase in structural disorder of the polymer films with increasing dose.

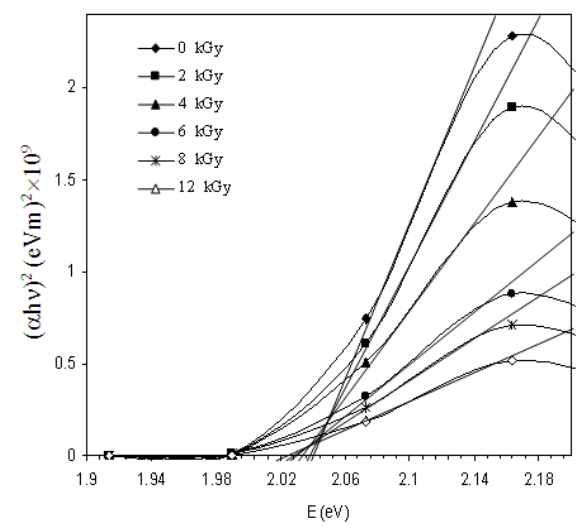

(a)

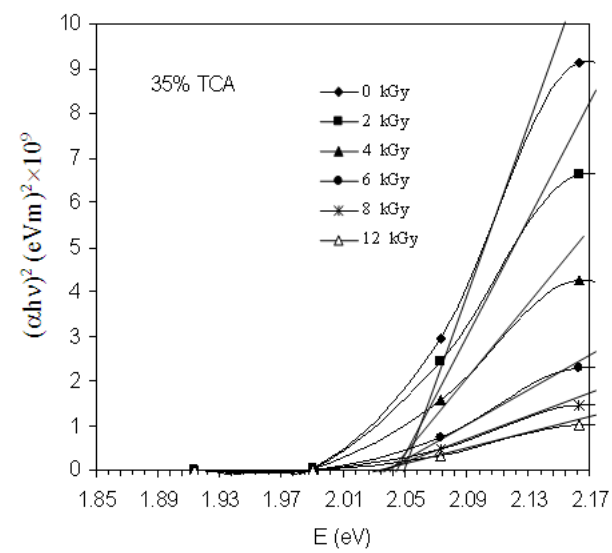

(b)

Fig. 9: Indirect allowed transition $(\alpha h v)^{2}$ versus hv for (a) $20 \% \mathrm{TCA}$; (b) $35 \% \mathrm{TCA}$ at different doses

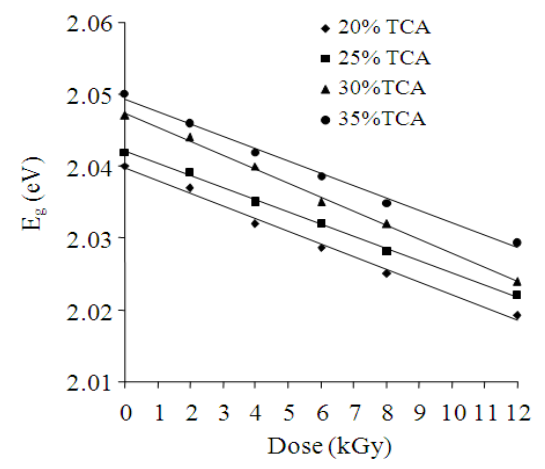

Fig. 10: Variation of the indirect energy band gaps with dose at different percentages of TCA 


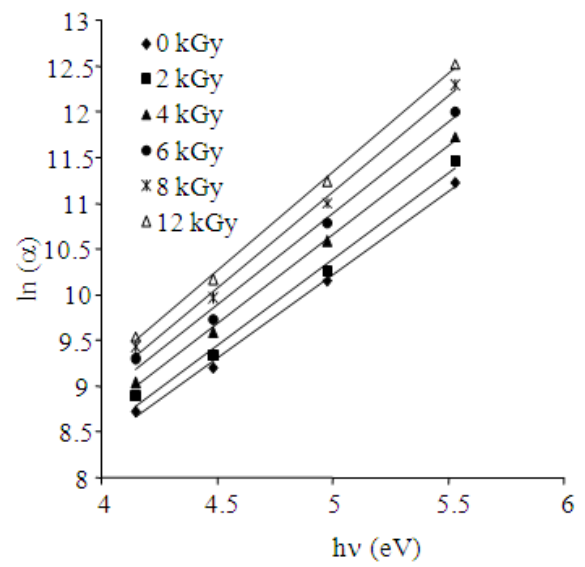

Fig. 11: $\ln (\alpha)$ versus energy (hv) for $20 \%$ of TCA at different doses

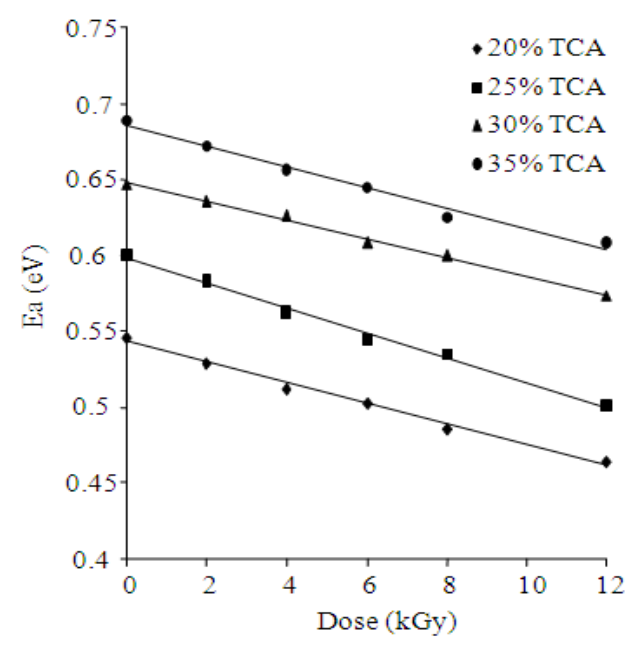

Fig. 12: Variation of the optical activation energy with dose at different percentages of TCA

The optical activation energy, $\Delta \mathrm{E}$, is the energy width of the tail of localized states in the band gap was valuated using the Urbach-edges method ${ }^{[22]}$ given by the formula:

$\alpha(\omega)=\alpha_{0} \exp (\hbar \omega / \Delta \mathrm{E})$

Where:

$\alpha_{0}=$ A constant

$\omega=2 \pi v$

The activation energy $\Delta \mathrm{E}$ of irradiated samples were determined from the slope of the straight lines of $\ln (\alpha)$ versus photon energy hv of Fig. 11. The results of $\Delta \mathrm{E}$ values for different doses are shown in Fig. 12.
It can be seen that $\Delta \mathrm{E}$ decreases with the increase of the radiation dose. The value of $\Delta \mathrm{E}$ is higher with the TCA concentration. There has been reported the value of $\triangle \mathrm{E}$ for UPVC films irradiated with electron beam was varied from 1.18-1.93 $\mathrm{eV}^{[23]}$ and for cable glass was from $0.27-0.96 \mathrm{eV}$.

\section{CONCLUSION}

These studies indicate that dyed PVA-TCA blends show good optical characteristics in terms of dose response and optical transitions. The remarkable dose response for both scattering and absorption methods shows the suitability of the blends for use as radiation indicators subject to temperature and humidity stability tests. The fitting of the dose-response curves $\mathrm{y}=\mathrm{y}_{0} \mathrm{e}^{-\mathrm{D} / \mathrm{D}_{0}}$ resulted in a linear relationship between the dose sensitive parameter $\mathrm{D}_{0}$ values and TCA concentrations. The optical energy band gaps are dependent on dose and TCA concentration for both direct and indirect allowed transitions. The decrease in the energy band gaps with increasing dose may be attributed to an increase in structural disorder of the polymer blends when the dose is increased. There is a shift in the energy band gap $\mathrm{E}_{\mathrm{g}}$ values towards lower energy with increasing dose leads to a shift of the optical activation energy $\Delta \mathrm{E}$ value towards the lower/higher energy with increasing dose.

\section{REFERENCES}

1. Preoneanu, S., R. Torcu, M. Brie and G. Mihilesan, 1995. Electrochemical and optical studies of metallic ion insertion in polypyrrole film. Mater. Sci. Forum, 191: 241-246. DOI: 10.4028/www.scientific.net/MSF.191.241

2. Armand, M., 1994. The history of polymer electrolytes. Solid State Ionics, 69: 309-319. http://cat.inist.fr/?aModele=afficheN\&cpsidt=4191432

3. Koksbang, R., I.I. Olsen and D. Shackle, 1994. Review of hybrid polymer electrolytes and rechargeable lithium batteries. Solid State Ionics, 69: 320-335.

http://www.cheric.org/research/tech/periodicals/vol _view.php/seq=265791

4. Abraham, K.M. and M.J. Alamgir, 1990. $\mathrm{Li}^{+}-$ conductive solid polymer electrolytes with liquidlike conductivity. Electrochem. Soc., 137: 1657-1658.

5. Reiche, A., J. Tubke, K. Siury, B. Sander, G. Fleischer and S. Wartewig, 1996. Gel electrolytes with plasticizers of different polarity. Solid State Ionics, 85: 121-127. 
6. Reiche, A., T. Steurich, B. Sander, P. Lobitz and G. Fleischer, 1995. Characterization, mechanism and model Ion transport in gel electrolytes. Electrochim. Acta, 40: 2153-2157. DOI: $10.1016 / 0013-4686(95) 00156-9$

7. Schartel, B., J. Wending and J.H. Wendorff, 1996. Cellulose/poly (vinyl alcohol) blends. I. Influence of miscibility and water content on relaxations. Macromolecules, 29: 1521-1527. DOI: 10.1021/ma 9506379

8. Huq, R., R. Koksbang, P.E. Tonder and G.C. Farrington, 1992. Effect of plasticizers on the properties of new ambient temperature polymer electrolyte. Electrochim. Acta, 37: 1681-1684. http://cat.inist.fr/?aModele $=$ afficheN\&cpsidt $=5610$ 853

9. Kovacs, A., M. Baranyai and L. Wojnarovits, 2000. Application of the Sunna dosimeter film in gamma and electron beam radiation processing. Radiat. Phys. Chem., 57: 691-695. DOI: 10.1016/S0969-806X(99)00435-1

10. Barakat, M.F., K. El-Salamawy, M. El-Banma, M. Abdel Hamid and A. Abdel-Rehim Taha, 2001. Radiation effects on some dyes in non-aqueous solvents and in some polymeric films Radiat. Phys. Chem., 61: 129-136. DOI: 10.1016/S0969806x(01)00181-5

11. Aleshin, A.N., N.B. Mironkov, A.V. Suvarov, J.A. Conklin, J.M. Su and R.B. Kaner, 1996. Transport Properties of ion-implanted and chemically doped Polyaniline Films. Phys. Rev. B: Condens. Matter, 54: 11638-11643. DOI: 10.1103/phys. Rev B.54.11638

12. Ogura, K., T. Saino, M. Nakayama and H. Shiigi, 1997.The humidity dependence of the electrical conductivity of a soluble Polyaniline-poly (vinyl alcohol) composite film. J. Mater. Chem., 7: 2363. DOI: 10. 1039/a 7054639

13. Devi, C.U., A.K. Sharma and V.V.R.N. Rao, 2002. Electrical and optical properties of pure and silver nitrate-doped polyvinyl alcohol films Mater. Lett., 56: 167-174. DOI: 10.1016/S0167-577x(02)004342

14. Abdel-Fattah, A.A., M. El-Kelany and A. AbdelRehim, 1996. Development of radiation sensitive indicator. Radiat. Phys. Chem., 48: 497-503. DOI: 10. 1016/ 0969-806x(96)00014-x

15. Abdel-Fattah, A.A., M. El-Kelany, F.A. Rehim and A.A. El-Miligy, 1997. UV-sensitive indicators based on bromophenol blue and chloral hydrate dyed poly (vinyl butyral). J. Photochem. Photobiol. A: Chem., 10: 291-297. DOI: 10.1016/S10106030(97)00195-0
16. Abdel-Fatah, A.A. and M. El-Kelany, 1998. Radiation sensitive indicator based on radiation chemical formation of acids in polyvinyl butyral films containing chloral hydrate. Radiat. Phys. Chem., 51: 317-325. DOI: 10. 1016/s0969806x(97)00258-2

17. Phukan, T., D. Kanjilal, T.D. Goswami and H.L. Das, 2003. Study of optical properties of swift heavy ion irradiated PADC polymer. Radiat. Measure., 36: 611-614. DOI: 10.1016/S1350-4487(03)002105

18. Abdel-Fattah, A.A., H.M. Abdel-Hamid and R.M. Radwan, 2002. Changes in the optical energy gap and ESR spectra of proton-irradiated unplasticized PVC copolymer and its possible use in radiation dosimetry. Nucl. Instr. Meth. Phys. Res. B, 196: 279-285. DOI: 10.1016/S0168$583 \times(02) 01299-5$

19. Al-Ani, K., I.H. Al-Hassany and Z.T. Al-Dahan, 1995. The optical properties and ac conductivity of magnesium phosphate glasses. J. Mater. Sci., 30: 3720-3729. DOI: 10.1007/BF 00351890

20. Mott, N.F. and E.A. Davis, 1979. Electronic Process in Non-crystalline Materials. 2nd Edn., Clarendom Press, ISBN: 10: 0198512880, pp: 604.

21. Arshak, A. and O. Korostynska, 2002. Gamma radiation dosimetry using tellurium dioxide thin film structures. Sensors, 2: 347-355. DOI: 10.3390/s20800347

22. Arshak, A., S. Zleetni and K. Arshak, 2002. Gamma radiation using optical and electrical properties of manganese phthalocyanine $(\mathrm{MnPc})$ thick film. Sensors, 2: 174-184. DOI: 10.3390/s20500174

23. Maged, A.F. and A.A. Abdel-Fattah, 1996. Changes in the fundamental absorption edge of cellulose nitrate and its possible use for radiation dosimetry. J. Mater. Sci., 31: 2775-2777. DOI: 10.1007/BF 00687314 